\title{
\# 03
}

2018-2019

Cuadernos de Gibraltar Gibraltar Reports

Revista Académica sobre la Controversia de Gibraltar Academic Journal about the Gibraltar Dispute http://doi.org/10.25267/Cuad_Gibraltar 


\title{
BREXIT Y COOPERACIÓN JUDICIAL CIVIL INTERNACIONAL: OPCIONES PARA GIBRALTAR
}

\author{
Miguel CHECA MARTÍNEZ1
}

\begin{abstract}
SUMARIO: I. LA SITUACIÓN DE GIBRALTAR EN EL MARCO DE LA COOPERACIÓN JUDICIAL CIVIL EN LA UE (DIPR DE LA UE). II. GIBRALTAR Y LOS CONVENIOS DE LA CONFERENCIA DE LA HAYA DE DIPR. III. EL ACUERDO DE RETIRADA DEL REINO UNIDO DE LA UE. IV. UN NUEVO MODELO DE COOPERACIÓN JUDICIAL CIVIL INTERNACIONAL ENTRE EL RU Y LA UE. V. LA CONVENIENCIA DE UN ACUERDO SEPARADO ENTRE EL RU Y LA UE PARA GIBRALTAR.
\end{abstract}

RESUMEN: La cooperación judicial civil internacional de los Estados Miembros de la UE con el Reino Unido puede quedar severamente reducida como consecuencia del Brexit si a la finalización del período transitorio, el 31 de diciembre de 2020, no ha sido aprobado un nuevo modelo de relaciones entre el RU y la UE que incluya acuerdos en materia de cooperación judicial civil. Otras soluciones multilaterales son posibles en el marco de la Conferencia de La Haya de DIPR o en relación con la adhesión del RU al Convenio de Lugano de 2007. Por el contrario, la situación de Gibraltar puede ser distinta a la del Reino Unido si el acuerdo separado de nuevas relaciones entre el RU y la UE en lo relativo a Gibraltar pudiese contener un repertorio suficiente de instrumentos de cooperación que permita salvaguardar la aplicación de al menos parte del Derecho Internacional Privado (DIPR) de la UE existente hasta la fecha.

PALABRAS CLAVE: Brexit, Cooperación Judicial Civil Internacional, Derecho Procesal Civil Internacional, conflicto de leyes, Derecho Internacional Privado, Conferencia de La Haya de Derecho Internacional Privado, Convenio De Lugano, Union Europea, Reino Unido, Gibraltar.

\section{BREXIT AND INTERNATIONAL CIVIL JUDICIAL COOPERATION: OPTIONS FOR GIBRALTAR}

ABSTRACT: International judicial cooperation for civil matters between Member States of the EU and the United Kingdom can be severely curtailed as a consequence of Brexit if upon the end

${ }^{1}$ Profesor Titular (Associate Professor) de Derecho Internacional Privado de la Universidad de Cádiz. Doctor en Derecho por la Universidad Complutense de Madrid. Trabajo realizado en el marco del Proyecto de I+D «La incidencia del "Brexit" en la cooperación transfronteriza entre Gibraltar-Campo de Gibraltar y Andalucía», PRY2015/19, IP Inmaculada González García, Proyecto seleccionado en la XI Convocatoria de Proyectos de Investigación de 2019 del Centro de Estudios Andaluces. 
of the transitory period, 31 December 2020, no new partnership between the UK and the UE has been approved including agreements on judicial civil cooperation. Other multilateral solutions are possible within the framework of The Hague Conference on Private International Law or in relation to the UK's ratification of the Lugano Convention 2007. Conversely, the situation of Gibraltar can be different to that of the UK if the separate agreement between the EU and UK in relation to Gibraltar includes a repertory of cooperation instruments sufficient enough to at least safeguard the application of part of EU Private International Law in force to date.

KEY WORDS: Brexit, International Judicial Cooperation for Civil Matters, International Civil Procedure Law, Conflict of Laws, Private International Law, Hague Conference on Private International Law, Lugano Convention, European Union, United Kingdom, Gibraltar.

\section{LA SITUACIÓN DE GIBRALTAR EN EL MARCO DE LA COOPERACIÓN JUDICIAL CIVIL EN LA UE (DIPR DE LA UE)}

El Art. 355.3 TFUE prevé que las disposiciones de los Tratados «se aplicarán a los territorios europeos cuyas relaciones exteriores asuma un Estado miembro», extendiendo así la aplicación del Derecho de la Unión Europea a Gibraltar, único overseas territory del RU que forma parte de la UE, salvo las excepciones previstas en el Acta de Adhesión. Por el contrario, esta extensión no es aplicable a la Isla de Man o las Islas del Canal (Jersey y Guernsey) que como resulta del Art. 355.5 TFUE no estarían dentro de la UE, pero sí entraron a formar parte de la Unión aduanera. Además, frente al resto de Estados miembros, es el Reino Unido quien actúa en representación de Gibraltar, particularmente en cuanto a la aplicación y transposición del Derecho europeo, como si fueran un único Estado. Así, el TJUE en su Sentencia de 13 de junio de 2017, asunto C-591/15, The Gibraltar Betting and Gaming Association Limited c. Commissioners for Her Majesty's Revenue and Customs, con fundamento en el art. 355.3 TFUE, concluyó que la prestación de servicios por operadores establecidos en Gibraltar a personas establecidas en Reino Unido constituye, de acuerdo con el Derecho de la UE, una situación en la que todos los elementos se circunscriben al interior de un único Estado miembro, por lo que no procede alegar la violación del art. 56 TFUE sobre libre prestación de servicios. $\mathrm{Si}$, por lo tanto, visto desde la UE el Reino Unido y Gibraltar son una unidad a los efectos de la libertad de prestación de servicios, por el contrario, también es cierto que no siendo el territorio de Gibraltar parte del Reino Unido, como único overseas territory británico que forma parte de la UE, y teniendo un amplio autogobierno, a veces ha podido ser visto o comportarse como una jurisdicción más, distinta a la del RU, es decir, algo cercano a un micro-estado 
en la UE, como ha podido comprobarse en su intento fallido de alegar la libre prestación de servicios frente al propio Reino Unido, o a través de la comercialización de sus propios derechos de prestación servicios financieros al resto de la UE (el RU ha garantizado que tras el Brexit podrá seguir haciéndolo hacia el propio RU sin limitaciones), o en materia de cooperación judicial civil internacional (donde corresponde a los tribunales de Gibraltar la aplicación recíproca prevista por los instrumentos europeos de DIPR) ${ }^{2}$.

En materia de cooperación judicial civil, Gibraltar se encuentra vinculado por los mismos instrumentos europeos que vinculan al Reino Unido en virtud del Art. 81 TFUE., lo que le permite atender sus necesidades de regulación como jurisdicción offshore donde las transacciones comerciales internacionales asumen una mayor importancia en un modelo económico orientado hacia las empresas multinacionales y las personas de elevado patrimonio neto y puede hacerlo con un repertorio normativo superior al de la mayoría de jurisdicciones offshore $e^{3}$. Cabe mencionar detalladamente que resultan de aplicación por las autoridades de Gibraltar y por las autoridades del resto de EEMM en relación con el territorio de Gibraltar los siguientes instrumentos:

a) En materia de competencia judicial internacional y reconocimiento mutuo, entre los Estados miembros, de las resoluciones judiciales y

${ }^{2}$ El estatuto jurídico de Gibraltar en el modelo constitucional británico es el de overseas territory. Su autogobierno es muy amplio en el marco de su propia Constitución (Gibraltar Constitution Order 2016), salvo en lo relativo a defensa, relaciones exteriores y seguridad interior que asume el Gobernador como representante del Reino Unido. Dentro de la UE como organización supraestatal Gibraltar asume un modelo que parte de su afirmación como entidad sub-estatal pero que dado su amplio autogobierno ha podido estar en una situación muy cercana a la de un micro-Estado en la UE (vid. Azopard, K. Sovereignty and the Stateless Nation: Gibraltar in the modern legal context, Oxford, Hart Publishing, 2009, pp. 61-126; reseñado por J. Trinidad, Cambridge L. J., 2011, pp. 272-274); TRINIDAD, J. Self-determination in disputed colonial territories, Cambridge, Cambridge University, 2018, pp. 120-133. Una vez fuera de la UE su situación puede considerarse análoga a la de los microestados como Andorra, Liechtenstein, San Marino y Mónaco, que son Estados que no pertenecen a la UE, pero con los que la UE debe llegar a acuerdos bilaterales (vid. D. Dozsa, «EU Relations with European Microstates. Happily ever after?», European L. J., 2008, pp. 93-104), naturalmente con el matiz de la soberanía británica sobre el territorio y la dificultad añadida de la necesidad de acuerdo previo con España.

${ }^{3}$ I. KAWALEY, «Why judicial cooperation in civil and commercial litigation in the British Offshore world matters: An Overview», Kawaley, I., Bolton, A., Mayor, R. Cross-Border Judicial Cooperation in Offshore Litigation, Londres, Wildy, Simmonds and Hill, 2016, pp. 3-16. 
extrajudiciales, así como su ejecución, serían aplicables el Reglamento (UE) 1215/2012 de 12 de diciembre de 2012, relativo a la competencia judicial, el reconocimiento y la ejecución de resoluciones judiciales en materia civil y mercantil (Bruselas I bis), el Reglamento (CE) 2201/2003 de 27 de noviembre de 2003, relativo a la competencia, el reconocimiento y la ejecución de resoluciones judiciales en materia matrimonial y de responsabilidad parental (Bruselas II bis) y Reglamento (CE) 4/2009 de 18 de diciembre de 2008, relativo a la competencia, la ley aplicable, el reconocimiento y la ejecución de las resoluciones y la cooperación en materia de obligaciones de alimentos (Bruselas III).

b) Para la notificación de documentos judiciales y extrajudiciales se encuentra en vigor el Reglamento (CE) 1393/2007 de 13 de noviembre de 2007, relativo a la notificación y al traslado en los Estados miembros de documentos judiciales y extrajudiciales en materia civil o mercantil.

c) La obtención de pruebas en el extranjero es regulada por el Reglamento (CE) 1206/2001 de 28 de mayo de 2001, relativo a la cooperación entre los órganos jurisdiccionales de los Estados miembros en el ámbito de la obtención de pruebas en materia civil o mercantil.

d) En cuanto a los procedimientos civiles especiales europeos aplicables en los Estados miembros son de aplicación el Reglamento (CE) 805/2004 de 21 de abril de 2004, por el que se establece un título ejecutivo europeo para créditos no impugnados, el Reglamento (CE) 1896/2006 de 12 de diciembre de 2006, por el que se establece un proceso monitorio europeo, el Reglamento (CE) 861/2007 de 11 de julio de 2007, por el que se establece un proceso europeo de escasa cuantía y el Reglamento (UE) 606/2013, de 12 de junio de 2013, relativo al reconocimiento mutuo de medidas de protección en materia civil; no así el Reglamento (UE) 655/2014 de 15 de mayo de 2014, por el que se establece el procedimiento relativo a la orden europea de retención de cuentas a fin de simplificar el cobro transfronterizo de deudas en materia civil y mercantil, puesto que el RU no participa del mismo.

e) En materia de procedimientos de insolvencia es aplicable el Reglamento (UE) 2015/848 de 20 de mayo de 2015, sobre procedimientos de insolvencia. 
f) La unificación de las normas aplicables en los Estados miembros en materia de conflictos de leyes es objeto del Reglamento (CE) 593/2008 de 17 de junio de 2008 sobre la ley aplicable a las obligaciones contractuales (Roma I) y del Reglamento (CE) 864/2007 de 11 de julio de 2007, relativo a la ley aplicable a las obligaciones extracontractuales (Roma II).

g) El Convenio de Lugano de 2007 relativo a la competencia judicial, el reconocimiento y la ejecución de resoluciones judiciales en materia civil y mercantil vincula a los EEMM de la UE relación con Islandia, Noruega y Suiza.

Sin embargo, el RU no participa (y en consecuencia Gibraltar tampoco) de los Reglamentos establecidos en materia de familia y sucesiones, respecto de los cuales el Reino Unido optó, de conformidad con el Art. 3 de su protocolo de adhesión al TUE y el TFUE, por no formalizar declaración de opting in y, por tanto, su preferencia fue la de quedar al margen de los instrumentos de la UE en este ámbito ${ }^{4}$ :

a) Reglamento (UE) 1259/2010 de 20 de diciembre de 2010 por el que se establece una cooperación reforzada en el ámbito de la ley aplicable al divorcio y a la separación judicial (Roma III).

b) Reglamento (UE) 650/2012, de 4 de julio de 2012, relativo a la competencia, la ley aplicable, el reconocimiento y la ejecución de las resoluciones, a la aceptación y la ejecución de los documentos públicos en materia de sucesiones mortis causa y a la creación de un certificado sucesorio europeo.

c) Reglamento (UE) 2016/1103, de 24 de junio de 2016, por el que se establece una cooperación reforzada en el ámbito de la competencia, la ley

\footnotetext{
${ }^{4}$ La situación de RU no es por tanto homogénea con la de otros EEMM de la UE que no disponen de esta posibilidad como pueda ser España. Irlanda tiene un protocolo similar al del RU y ha optado por quedar fuera de los mismos Reglamentos. Dinamarca, por su parte, se encuentra fuera del DIPR de la UE según su protocolo de adhesión, de manera que sólo por acuerdo bilateral entre la UE y Dinamarca se ha establecido la aplicación del Reglamento Bruselas I bis, el Reglamento Bruselas III y el Reglamento sobre notificaciones judiciales y extrajudiciales. En este sentido, el RU no ha sido la única excepción a la falta de uniformidad del DIPR en toda la UE (vid. P. J. CARDwELL, «The end of exceptionalism and a strengthening of coherence. Law and legal integration in the EU Post-Brexit», Journal of Common Market Studies, 2009, pp. 1407-1418; N. WALKER, «Sovereignty and Differentiated Integration in the European Union», European L. J., 1998, pp. 355-388).
} 
aplicable, el reconocimiento y la ejecución de resoluciones en materia de regímenes económicos matrimoniales.

d) Reglamento (UE) 2016/1104, de 24 de junio de 2016, por el que se establece una cooperación reforzada en el ámbito de la competencia, la ley aplicable, el reconocimiento y la ejecución de resoluciones en materia de efectos patrimoniales de las uniones registradas.

\section{GIBRALTAR Y LOS CONVENIOS DE LA CONFERENCIA DE LA HAYA DE DIPR}

El Reino Unido con ocasión de la ratificación o adhesión a Convenios de la Conferencia de La Haya debe declarar la extensión territorial de la aplicación territorial del instrumento convencional en relación con los territorios que no son Reino Unido, sino Crown dependencies (entre los que se encuentran la Isla de Man y las Islas de Jersey y Guernsey) o British Overseas Territories (entre los que se encuentra Gibraltar junto a otros territorios no europeos: Bermuda, British Virgin Islands, Cayman Islands, etc.). Hasta la fecha Gibraltar se encuentra vinculado por los siguientes instrumentos convencionales de la Conferencia de La Haya de DIPr:

a) Convenio de 5 de octubre de 1961 sobre los conflictos de leyes en materia de forma de las disposiciones testamentarias desde 14.02.1965.

b) Convenio de 5 de octubre de 1961 suprimiendo la exigencia de legalización de los documentos públicos extranjeros desde 25.04.1965.

c) Convenio de 15 de noviembre de 1965 sobre la notificación o traslado en el extranjero de documentos judiciales y extrajudiciales en materia civil o comercial desde 10.07.1970.

d) Convenio de 18 de marzo de 1970 sobre la obtención de pruebas en el extranjero en materia civil o comercial desde el 20.01.1979.

e) Convenio de 1 de junio de 1970 sobre el reconocimiento de divorcios y de separaciones legales desde 28.01.1977.

f) Convenio de 1 de julio de 1985 sobre la ley aplicable al trust y a su reconocimiento desde 1.01.1992. 
g) Convenio de 19 de octubre de 1996 relativo a la competencia, la ley aplicable, el reconocimiento, la ejecución y la cooperación en materia de responsabilidad parental y de medidas de protección de los niños, en vigor desde 1.11.2012.

El RU es parte en otros Convenios de la Conferencia de La Haya respecto de los cuales no ha manifestado la extensión al territorio de Gibraltar:

a) Convenio de 25 de octubre de 1980 sobre los aspectos civiles de la sustracción internacional de menores en vigor desde 1.08.1986.

b) Convenio de 29 de mayo de 1993 relativo a la protección del niño y a la cooperación en materia de adopción internacional en vigor desde 1.06.2003.

c) Convenio 13 enero de 2000 sobre protección de adultos, en vigor para el RU desde 1.01.2009, pero sólo en relación a Escocia.

Por último, el RU participa de otros Convenios de La Haya de DIPR más recientes, pero no por su ratificación o adhesión propia, sino porque ha sido realizada por la UE como organización supraestatal con efectos para todos los EEMM de la UE:

a) El Convenio de La Haya de 2005 sobre acuerdos de elección de foro (en vigor entre la UE, México, Singapur y Montenegro) vincula al RU desde 1.10.2015 en cuanto que es un EM de la UE y también a Gibraltar ${ }^{5}$. Para continuar vinculado por este instrumento tras su salida de la UE, no sólo con los terceros Estados que ahora participan del mismo, sino también con los propios EEMM de la UE en su futura condición de tercer Estado, el RU presentó su adhesión al mismo el 28.12.2018 con extensión al territorio de Gibraltar. Sin embargo, la adhesión ha permanecido en suspenso hasta el 1 de febrero de 2020 y ha sido ahora retirada el 31 de enero de 2020, si bien el RU ha anunciado su intención de depositar un nuevo instrumento de adhesión antes de que termine el periodo transitorio, siempre en atención al desarrollo de las negociaciones sobre el nuevo modelo de relaciones entre el RU y la UE'.

${ }^{5}$ La recepción en el Derecho de Gibraltar fue efectuada mediante la Civil Jurisdiction and Judgments Act 1993 (Amendment No.2) Regulations 2015.

${ }^{6}$ La regulación necesaria para la implementación del Convenio de La Haya de 2005 en un entorno de ratificación independiente del Reino Unido, incluidas reglas transitorias, fue in- 
b)El Convenio de La Haya de 23 de noviembre de 2007 sobre Cobro Internacional de Alimentos para los Niños y otros Miembros de la Familia vincula igualmente al RU y a Gibraltar en cuanto la ratificación del mismo fue efectuada por la UE con efectos desde 1.08.2014 para todos los $\mathrm{EEMM}^{7}$. El Reino Unido posteriormente ha depositado su instrumento de adhesión en nombre propio con extensión al territorio de Gibraltar el 31.07.2019, pero con eficacia condicionada al resultado de las negociaciones del Brexit. Tras la aprobación del Acuerdo de Retirada su entrada en vigor para RU y Gibraltar no ha sido posible y el instrumento de ratificación ha sido retirado el 31 de enero de 2020, aunque desde luego todo hace pensar que se volverá a depositar un nuevo instrumento de ratificación si no llega a existir un nuevo modelo de cooperación judicial civil entre el RU y la UE.

\section{EL ACUERDO DE RETIRADA DEL REINO UNIDO DE LA UE}

\section{Disposiciones transitorias en materia de cooperación judicial civil}

El Acuerdo sobre la Retirada del Reino Unido de Gran Bretaña e Irlanda del Norte de la Unión Europea ${ }^{8}$ ha entrado en vigor el 1 de febrero, sin apenas novedades en cuanto a cooperación judicial civil internacional respecto a la versión anterior del Acuerdo de Retirada- negociado por el gobierno de Theresa May- y que fue rechazado por el Parlamento británico provocando las elecciones generales que han llevado a Boris Johnson al poder y a la aprobación por el Parlamento británico de un nuevo Acuerdo de Retirada con modificaciones menores sobre el anterior, a excepción de la nueva solución otorgada al problema de la cláusula de salvaguardia respecto de Irlanda del Norte.

cluida en la Civil Jurisdiction and Judgments (Hague Convention on Choice of Court Agreements 2005) (EU Exit) Regulations 2018, S.I. 2018 N 1124.

${ }^{7}$ Su incorporación en el Derecho de Gibraltar se ha producido mediante modificaciones legislativas (amendments) y legislación secundaria (subsidiary legislation), en vigor desde 22.11.2018: International Recovery of Maintenance (2007 Hague Convention) Regulations 2018, Maintenance Proceedings (2007 Hague Convention) Rules 2018, Civil Jurisdiction and Judgments Act (2007 Hague Convention) Regulations 2018, Maintenance Act (2007 Hague Convention) Regulations 2018 y Magistrates' Court Act (2007 Hague Convention) Regulations 2018.

${ }^{8}$ DO L 29, 31.1.2020. 
Como es bien conocido, el periodo transitorio general previsto por el artículo 126 del Acuerdo de Retirada finalizará el 31 de diciembre de 2020, salvo que se acuerde una ampliación del mismo, que podrá ser decidida antes del 1 de julio de 2020 y que podrá extender el período transitorio hasta un máximo de uno o dos años adicionales. Durante este período transitorio el Derecho de la Unión será aplicable y será interpretado por y en relación al Reino Unido de conformidad con los mismos métodos y principios generales que los aplicables dentro de la Unión (Art. 127.3). En particular, el Tribunal de Justicia de la Unión Europea será competente de conformidad con lo dispuesto en los Tratados (Art. 131).

Pero el Acuerdo de Retirada contiene además un Titulo (el Sexto) dedicado a la Cooperación judicial en curso en materia civil y mercantil (Arts. 66 a 69) que añade disposiciones transitorias específicas que son de extraordinaria relevancia práctica.

En materia de competencia judicial, reconocimiento y ejecución de resoluciones judiciales y cooperación conexa entre las autoridades centrales, el Artículo 67 del Acuerdo de Retirada establece que en el Reino Unido, y en los Estados miembros en las situaciones que incumban al Reino Unido, respecto de los procesos judiciales incoados antes del final del período transitorio y respecto de los procesos o acciones que tengan relación con tales procesos judiciales con arreglo a los artículos 29, 30 y 31 del Reglamento (UE) 1215/2012, el artículo 19 del Reglamento (CE) 2201/2003 o los artículos 12 y 13 del Reglamento (CE) 4/2009, seguirán siendo de aplicación las normas de competencia judicial internacional y las normas sobre litispendencia y conexidad contenidas en los respectivos Reglamentos, siendo especialmente importante aquí la primacía que el Art. 32.1 Reglamento 1215/2012 otorga a los acuerdos de elección de foro en las situaciones de litispendencia. Sin embargo, al margen de lo previsto para situaciones de litispendencia, no se recoge una eficacia general de los acuerdos de elección de foro formalizados antes del final del período transitorio si el litigio surge después de tal período, como había solicitado la parte británica en las negociaciones, de modo que, en ausencia de un nuevo acuerdo de cooperación judicial civil, la determinación de la eficacia exclusiva de las cláusulas de elección de tribunales ingleses en caso de que la demanda no sea presentada ante la jurisdicción elegida quedará a lo previsto por la regulación de la competencia judicial internacional de cada EM. 
En materia de reconocimiento y ejecución de decisiones, en el Reino Unido, y en los Estados miembros en las situaciones que incumban al Reino Unido, el Art. 67.2 establece que, respecto del régimen de reconocimiento y la ejecución de resoluciones, se estará al momento de la incoación del procedimiento, que deberá ser anterior a la finalización del período transitorio, y no a la fecha de la adopción de la resolución judicial, que podrá ser posterior a la finalización de dicho período; sin embargo, en relación con los documentos públicos, acuerdos y transacciones judiciales se estará a su fecha de formalización, aprobación o registro, según corresponda: a) el Reglamento (UE) 1215/2012 se aplicará al reconocimiento y la ejecución de las resoluciones dictadas en procesos judiciales incoados antes del final del período transitorio, así como a los documentos públicos formalizados o registrados oficialmente y las transacciones judiciales aprobadas o celebradas antes del final del período transitorio; b) el Reglamento (CE) 2201/2003 se aplicará al reconocimiento y la ejecución de las resoluciones dictadas en procesos judiciales incoados antes del final del período transitorio, a los documentos públicos con fuerza ejecutiva formalizados o registrados y a los acuerdos celebrados antes del final del período transitorio; c) el Reglamento (CE) 4/2009 se aplicará al reconocimiento y la ejecución de las resoluciones dictadas en procesos judiciales incoados antes del final del período transitorio, a las transacciones judiciales aprobadas o celebradas y a los documentos públicos con fuerza ejecutiva formalizados o registrados antes del final del período transitorio; d) el Reglamento (CE) 805/2004 se aplicará a las resoluciones dictadas en procesos judiciales incoados antes del final del período transitorio, a las transacciones judiciales aprobadas o celebradas y a los documentos públicos con fuerza ejecutiva formalizados antes del final del período transitorio, siempre que la certificación como título ejecutivo europeo se haya solicitado antes del final del período transitorio.

Por su parte, el art. 67.3 establece adicionalmente que: a) el capítulo IV del Reglamento (CE) 2201/2003 se aplicará a las solicitudes y demandas recibidas por la autoridad central o cualquier otra autoridad competente del Estado requerido antes del final del período transitorio; b) el capítulo VII del Reglamento (CE) 4/2009 se aplicará a las solicitudes de reconocimiento o ejecución a que se refiere el apartado 2, letra c), del presente artículo y a las solicitudes que reciba la autoridad central del Estado requerido antes del 
final del período transitorio; c) el Reglamento (UE) 2015/848 se aplicará a los procedimientos de insolvencia y a las acciones a que se refiere el artículo 6, apartado 1, de dicho Reglamento, siempre que el procedimiento principal se haya incoado antes del final del período transitorio; d) el Reglamento (CE) 1896/2006 se aplicará a las peticiones de requerimiento europeo de pago presentadas antes del final del período transitorio; cuando, a raíz de dicha petición, se traslade el proceso con arreglo al artículo 17, apartado 1, de dicho Reglamento, se considerará que dicho proceso ha sido incoado antes del final del período transitorio; e) el Reglamento (CE) 861/2007 se aplicará a los procesos de escasa cuantía en los que la demanda haya sido presentada antes del final del período transitorio; f) el Reglamento (UE) 606/2013 se aplicará a los certificados expedidos antes del final del período transitorio.

En materia de conflicto de leyes el Artículo 66 del Acuerdo de Retirada establece el criterio temporal que determinará la aplicabilidad en el Reino Unido del Reglamento 593/2008 sobre ley aplicable a las obligaciones contractuales respecto de los contratos celebrados antes del final del período transitorio y del Reglamento 864/2007 sobre ley aplicable a las obligaciones extracontractuales respecto de los hechos generadores de daño, cuando dichos hechos se produzcan antes del final del período transitorio. Los Reglamentos 593/2008 y 864/2007 seguirán siendo aplicables a contratos celebrados y hechos producidos más allá del final período transitorio, pero será a través de la incorporación o mantenimiento de vigencia por el ordenamiento jurídico del Reino Unido de dichos Reglamentos en virtud de la European Union (Withdrawal) Act, siempre que el legislador británico no opte en el futuro por introducir una nueva regulación en la materia. Por el contrario, para los EEMM de la UE, tratándose los Reglamentos 593/2008 y 864/2007 de instrumentos de alcance universal en cuanto a su ámbito espacial de aplicación seguirán siendo aplicables cualquiera que sea la ley aplicable y con independencia de los vínculos que pudieran existir entre el supuesto y el RU (si bien, el RU tendrá la consideración de tercer Estado a los efectos de los arts. 3.4 y 7 RRI o el art. 14.3 del RRII) $)^{9}$.

En cuanto a los procedimientos de cooperación judicial en sentido estricto, en el Reino Unido, así como en los Estados miembros en situaciones que incumban al Reino Unido, el criterio temporal a tener en cuenta será el del ${ }^{9}$ De Miguel Asensio, P. «El borrador de Acuerdo de Retirada del Reino Unido y los litigios en materia mercantils, La Ley Unión Europea, 30 de abril 2018, pp. 1-6. 
momento de la recepción de las solicitudes de cooperación: a) el Reglamento (CE) 1393/2007 sobre notificaciones se aplicará a los documentos judiciales y extrajudiciales que reciban a los efectos de su notificación o traslado antes del final del período transitorio: i) un organismo receptor, ii) una entidad central del Estado en el que deba realizarse la notificación o el traslado, o iii) los agentes diplomáticos o consulares, los servicios postales o los agentes judiciales, funcionarios u otras personas competentes del Estado requerido a que se refieren los artículos 13, 14 y 15 de dicho Reglamento; b) el Reglamento (CE) 1206/2001 sobre obtención de pruebas se aplicará a las solicitudes que reciban antes del final del período transitorio: i) un órgano jurisdiccional requerido, ii) un órgano central del Estado en el que se solicita que se obtenga la prueba, o iii) un órgano central o autoridad competente a que se refiere el artículo 17, apartado 1, de dicho Reglamento.

\section{El Protocolo sobre Gibraltar}

El Acuerdo de Retirada contiene un Protocolo respecto de Gibraltar que es aplicable, en particular, durante el período transitorio. En efecto, el Protocolo sobre Gibraltar, con excepción de su artículo 1, dejará de aplicarse al final del período transitorio (Art. 185). Se crea también un Comité especializado sobre cuestiones relacionadas con la aplicación del Protocolo sobre Gibraltar que estará compuesto por representantes de la Unión y representantes del Reino Unido (Art. 165). España, en virtud de lo establecido en la Decisión del Consejo 2020/135 (Art. 2) relativa a la celebración del Acuerdo de Retirada podrá solicitar que el representante de la Comisión vaya acompañado de un representante del Reino de España en las reuniones del Comité especial sobre cuestiones relacionadas con la aplicación del Protocolo sobre Gibraltar.

El Protocolo «toma nota» de los cuatro Memorandos de Entendimiento ya celebrados entre el Reino de España y el Reino Unido el 29 de noviembre de 2018 en relación con los derechos de los ciudadanos, el tabaco y otros productos, la cooperación en materia de medio ambiente y la cooperación en materia policial y aduanera, así como del Acuerdo alcanzado el 4 de marzo de 2019 entre el Reino de España y el Reino Unido en materia de fiscalidad y protección de los intereses financieros en relación con Gibraltar.

El Acuerdo fiscal se encuentra aún pendiente de aprobación parlamentaria en ambos Estados y entrará en vigor en la fecha de la última de las notificaciones de las Partes indicando que han completado sus procedimientos 
internos de aprobación, surtiendo efectos en relación con personas físicas y jurídicas para los periodos impositivos que comiencen desde la fecha de entrada en vigor del Acuerdo, o bien, cuando no haya periodos impositivos, respecto de las obligaciones fiscales devengadas desde la fecha de entrada en vigor $^{10}$. Un aspecto institucional novedoso del Acuerdo fiscal es que, siendo el primer Acuerdo bilateral entre RU y España en relación con Gibraltar, por primera vez se establecen obligaciones y relaciones directas entre autoridades fiscales españolas y las autoridades fiscales de Gibraltar e incluso cabe entender que con otras autoridades de Gibraltar expresamente mencionadas en el Acuerdo como el Registro mercantil o el Registro de la Propiedad. En la memoria (Explanatory memorandum) que acompaña al texto del Tratado en la versión publicada por el Reino Unido con ocasión del inicio del trámite de su aprobación parlamentaria se explicita que «The Government of Gibraltar have led the negotiations for the UK» de modo que se trata de un acuerdo bilateral entre Reino Unido y España, pero negociado por Gibraltar en nombre del Reino Unido y con efectos únicamente para el territorio de Gibraltar. No es de extrañar por tanto que en España haya sido criticado por aquellos que entienden que supone el reconocimiento de la existencia de estructuras propias de Estado en Gibraltar.

Cabe mencionar aquí que en contextos multilaterales (tratados internacionales de la Conferencia de La Haya de DIPR e instrumentos de la UE), las relaciones directas de Gibraltar con otros Estados se intentan evitar mediante el procedimiento indirecto de comunicaciones conocido como post-boxing a través de la Gibraltar Liaison Unit del Foreign Office del Reino Unido, con sede en Londres, de modo que la identificación de la autoridad competente gibraltareña y sus comunicaciones en relación con la aplicación de esos Tratados internacionales o instrumentos de la UE debe hacerse y ser comunicada al resto de Estados a través del Foreign Office ${ }^{11}$.

${ }^{10}$ FAlCón y Tella, R. «El nuevo acuerdo fiscal con Gibraltar, pendiente de ratificación», Quincena fiscal, núm. 20, 2019, págs. 9-14. El texto del Tratado fiscal fue publicado en BOCG el 14 de febrero de 2018, iniciándose el trámite de autorización parlamentaria. De manera similar, el texto se encuentra a la espera ratificación por el Reino Unido.

${ }^{11}$ Régimen relativo a las autoridades de Gibraltar en el contexto de ciertos Tratados internacionales acordado por España y el Reino Unido el 19 de diciembre de 2007 y Régimen acordado relativo a las autoridades de Gibraltar en el contexto de los instrumentos de la UE y CE y Tratados conexos, de 19 de abril de 2000 (vid. Rodríguez Benot, A. «Acuerdos de 
En cuanto al contenido efectivo del Protocolo, sólo su artículo $1^{\circ}$ sobre Derechos de los ciudadanos y, en particular, los trabajadores fronterizos, tendrá eficacia más allá del periodo transitorio. El resto de previsiones sobre transporte aéreo (Art. 2), cuestiones fiscales (Art. 3), medio ambiente y pesca (Art. 4) y cooperación policial y aduanera (Art. 5) parecen tener una vigencia, en principio, limitada al período transitorio. El Protocolo sobre Gibraltar no contiene previsiones sobre cooperación judicial en materia civil, por lo que su existencia más allá del período transitorio dependerá de la extensión a Gibraltar del régimen de cooperación judicial civil que pueda ser acordado en el marco de las nuevas relaciones entre el RU y la UE.

\section{UN NUEVO MODELO DE COOPERACIÓN JUDICIAL CIVIL INTERNACIONAL ENTRE EL RU Y LA UE}

\section{Un nuevo Acuerdo de relación futura entre el $R U$ y la UE}

Si los años pasados han sido de incertidumbre aún más lo serán los once meses hasta la finalización del período transitorio a fines de diciembre de 2020. Si con el Acuerdo de Retirada se ha conseguido evitar un Brexit caótico o desordenado (wild Brexit) lo que queda aún por ver es si estaremos ante un soft Brexit (en caso de lograr un Acuerdo de amplio sobre las relaciones futuras) o un hard Brexit (ante la inexistencia de un nuevo modelo de relaciones o su limitación a un modelo de libre comercio). Pese a la existencia del Acuerdo de Retirada todo indica que se tratará de un hard Brexit. Resulta incluso dudoso que en el período de tiempo de once meses pueda acordarse un nuevo marco de relaciones entre el RU y la UE por liviano que sea. Por el momento, los términos deseados de una relación futura por una y otra parte no pueden ser más opuestos. El Gobierno del Reino Unido ha insistido (discurso de Boris Johnson titulado «Unleashing Britain's Potential» de 3.02.2020) en alcanzar únicamente un acuerdo de libre comercio basado en el existente entre la UE y Canadá y, por el contrario, la UE ofrece un modelo de acuerdo más ambicioso de libre comercio (sin aranceles ni cuotas) pero donde las regulaciones a ambos lados del Canal deberían estar alineadas (level-playing field) en múltiples cooperación entre España y el Reino Unido de 19 de abril de 2000 a propósito de Gibraltar», REDI, 2000, pp. 273-275; CheCA MarTínez, M. , «La cooperación judicial civil entre España y Gibraltar» en Del Valle Gálvez A. - González García , I. (Eds.) J. Gibraltar 300 años, Universidad de Cádiz, 2004, págs. 353-360). 
ámbitos regulatorios (fiscal, social, medioambiental, etc.). La hipótesis del fracaso de las negociaciones futuras no es descartable ante el rechazo ya manifestado por parte británica a esa alineación o nivelación regulatoria, así como la amenaza ya verbalizada de retirarse de las negociaciones en junio si no ha habido ningún avance para ese momento y ambas partes siguen enfrentadas en cuanto a sus líneas rojas iniciales. Si bien existe un Acuerdo de Retirada con claras reglas transitorias en materia de cooperación judicial civil internacional podría darse igualmente que, al final del período transitorio (la parte británica insiste en declarar que no lo ampliará más allá del 31 de diciembre de 2020), no exista un acuerdo sobre un nuevo modelo de relaciones entre el RU y la UE y, por tanto, tampoco un acuerdo en materia de cooperación judicial civil por limitado que fuese, de manera que la mayoría de las previsiones sobre el horizonte del no-deal que fueron realizadas en algún momento de fracaso de las negociaciones habrán de ser reactivadas.

El Reino Unido expresó hace bastante tiempo y en más de una ocasión su interés en establecer tras su salida un marco de relaciones con la Unión que incluyese un régimen de cooperación de amplio alcance, mediante un acuerdo tan completo y efectivo como resultase posible, en materia de competencia judicial internacional, ley aplicable y reconocimiento y ejecución de resoluciones, en línea con los principios de los instrumentos de la Unión en este ámbito en los que actualmente participa ${ }^{12}$. Es decir, la voluntad de salvar el acervo del Derecho de la UE en este ámbito, pero a través de un nuevo cauce de aplicación que sería el de un acuerdo bilateral dentro del nuevo marco de relaciones con la UE. La propuesta británica no sólo era relativa al ámbito de familia, un ámbito material en que la propia UE expresó su voluntad de cooperación estrecha, sino también relativa a la protección de consumidores y trabajadores, así como en general en materia civil y mercantil por su importancia para negocios y empresas, incluyendo las reglas actuales en materia de insolvencia. Por el contrario, la posición negociadora inicial de la Comisión europea sobre cooperación civil fue mucho más escueta y sobre todo centrada únicamente en las reglas transitorias de aplicación de los distintos instru-

\footnotetext{
${ }^{12}$ HM GOVERnMent: Providing a cross-border civil judicial cooperation framework: A future partnership paper, agosto 2017; Framework, for the UK-EU partnership: Civil Judicial Cooperation, junio 2018; The future relationship between the United Kingdom and the European Union, Julio 2018.
} 
mentos europeos una vez se hubiese producido la salida del Reino Unido a la finalización del período transitorio ${ }^{13}$.

La Declaración Política en la que la UE y el Reino Unido exponen el marco de sus relaciones futuras ${ }^{14}$, texto que acompaña al Acuerdo de Retirada, deja claro que la prioridad para la Unión es la cooperación judicial en materia penal (apartados 80 a 89 de la Declaración, en particular apartado 88). Por el contrario, la cooperación judicial en materia civil sólo es mencionada de forma parcial y además no de forma autónoma, sino tangencialmente por su relación con la movilidad de las personas. Así, el apartado 55 establece que las partes «confirman su compromiso con la aplicación efectiva de los instrumentos jurídicos existentes en materia de Derecho de familia en los que sean Partes; la Unión toma nota de la intención del Reino Unido de adherirse al Convenio de La Haya de 2007 sobre obligaciones alimenticias por el que actualmente se encuentra vinculado debido a su pertenencia a la Unión» y el apartado 56 añade que las partes «estudiarán las posibilidades de cooperación judicial en asuntos matrimoniales, cuestiones de responsabilidad parental y otros temas conexos». Es decir, se prevé el mantenimiento de los instrumentos de DIPR de la UE en materia de Derecho de familia vigentes en el RU, que no son muchos pero resultan de gran importancia, a saber, sólo el Reglamento Bruselas II bis sobre materia matrimonial y responsabilidad parental y el Reglamento Bruselas III sobre obligaciones de alimentos, con el añadido de la futura ratificación por el RU del Convenio de La Haya de $2007^{15}$.

Naturalmente, el acuerdo de cooperación podría ser más amplio a tenor de lo dispuesto en el apartado 3 de la introducción a la Declaración al esta-

${ }^{13}$ Position paper on Judicial Cooperation in Civil and Commercial matters, 17 Julio 2017. ${ }^{14}$ DO C 34, 31.1.2020.

${ }^{15}$ Alvarez Gonzalez, S. «Persona y familia en el Espacio de Libertad, Seguridad y Justicia tras el Brexit», La Ley Unión Europea, número 63, 31 de octubre de 2018; Smith, G. Hodson, D., Le Grice, V. «Brexit and international family law: a pragmatic approach to divorce and maintenance», Family Law, 2018, pp. 1554-1563; N. Lowe, «Some reflections on the options for dealing with international family law following Brexit», Family Law, 2017, pp. 399-406; ID, "What are the implications of the Brexit vote for the law on international child abduction», CFLQ, 2017, pp. 253-266; DutTA, A. «Brexit and international family law from a continental perspective», CFLQ, 2017, pp. 199-212; BEAumont, P. «Private international law concerning children in the UK after Brexit: comparing Hague Treaty law with EU Regulations», CFLQ, 2017, pp. 213-232; LAMONT, R. «Not a European Family: Implications of Brexit for International Family Law», CFLQ, 2017, pp. 267-280. 
blecer que en la medida en que ambas partes durante las negociaciones consideren que pueda redundar en beneficio mutuo, las relaciones futuras podrán abarcar ámbitos de cooperación adicionales a los previstos en la Declaración Política. Sería deseable, en efecto, que durante las negociaciones sobre la continuidad de los instrumentos de DIPR de la UE en materia de familia pudiera percibirse la conveniencia de ampliar el ámbito de la cooperación judicial civil a los ámbitos generales en materia civil y mercantil (Bruselas I bis), la cooperación entre autoridades judiciales (notificaciones judiciales y extrajudiciales, así como obtención de pruebas), los procedimientos europeos (título ejecutivo europeo, monitorio europeo, y reclamación de menor cuantía) y la insolvencia. Sin embargo, nada en la actualidad parece sugerir esa posibilidad. Es más, si la Declaración política tiene alguna utilidad a fin de señalar los ámbitos materiales de las negociaciones futuras parece que sólo la cooperación judicial civil en materia de familia será un objetivo de negociación para la UE y sólo por tratarse de un asunto relacionado con la negociación del acuerdo relativo a movilidad de las personas físicas.

Por el momento, al inicio de las negociaciones en marzo de 2020 para establecer un nuevo modelo de relaciones («a new partnership»), las previsiones no pueden ser muy optimistas. Con independencia de las diferencias de modelos generales a los que las dos partes quieren llegar, el hecho es que la cooperación judicial internacional en materia civil no aparece mencionada en las Directrices para la negociación que han sido presentadas por la Comisión el 3 de febrero de 2020 para su aprobación por el Consejo en la forma de Recomendación ${ }^{16}$. La cooperación judicial en materia penal sí aparece entre los objetivos negociadores, pero la cooperación judicial en materia civil no es mencionada ni siquiera de forma accesoria a las negociaciones en materia de movilidad de las personas físicas. Quizás se trate de una hábil técnica negociadora, teniendo en cuenta que en el pasado ha sido la parte británica la más insistente en alcanzar un amplio acuerdo en materia de cooperación judicial civil, pero nada parece confirmarlo por el momento. En cuanto al mandato negociador británico, hecho también publico en febrero, el RU sí propone un acuerdo en materia de cooperación judicial pero no se incluye la idea de la futura vigencia bilateral de ningún Reglamento europeo y se propone, por el contrario, seguir avanzando mediante los instrumentos multilaterales de la Conferencia de La Haya de

${ }^{16}$ COM (2020) 35 final. 
Derecho internacional privado y mediante la adhesión del Reino Unido como parte contratante independiente al Convenio de Lugano de $2007^{17}$.

\section{2.- Las soluciones multilaterales}

Si la hipótesis de las soluciones bilaterales que permitan la supervivencia de Reglamentos europeos en el marco de un nuevo Acuerdo de relación entre el RU y la UE parece abandonada en la actualidad, es decir, al inicio de las negociaciones para un nuevo modelo de relaciones, por el contrario, parece tomar forma la hipótesis del acuerdo para la búsqueda de soluciones en contextos multilaterales, en lo esencial dos: a) el Convenio de Lugano de 2007, b) la Conferencia de La Haya de Derecho Internacional Privado.

La ratificación por el RU del Convenio de Lugano de 2007, que en la actualidad sólo le resulta vinculante por su condición de EM de la UE, sólo sería posible, tras la salida del Reino Unido de la UE, por invitación de las partes (la UE o alguno de los tres Estados miembros de la EFTA que forman parte del Convenio: Suiza, Noruega e Islandia, pero no Liechtenstein) y el proceso de ratificación posterior por todas las partes podría alargarse en el tiempo. Si llegase a producirse esta adhesión del RU representa desde luego una solución interesante puesto que el Convenio resultaría aplicable tanto a las relaciones entre el RU y los EEMM de la UE, como a las relaciones del RU con Suiza, Noruega e Islandia. Sin embargo, debe recordarse que el Convenio Lugano 2007 no tiene prevista por el momento ninguna ronda de negociaciones dirigidas a su modificación y que se corresponde con el contenido del Reglamento 44/2001, antecedente del actual Reglamento 1215/2012, de manera que su ratificación no dejaría de suponer un cierto retroceso técnico en las relaciones del RU con el resto de EEMM de la UE. Por el momento, los países de la EFTA (Suiza, Noruega e Islandia) han manifestado su voluntad favorable a que el RU formalice su adhesión antes del final del período transitorio, resta por ver la posición de la UE que resulta asimismo fundamental.

\footnotetext{
${ }^{17}$ Las directrices del mandato negociador británico se encuentran en el documento titulado «The Future Relationship with the EU: the UK's approach to negotiations», 27 febrero 2020, y, sin mencionar explícitamente a Gibraltar, mantiene expresamente que el Reino Unido negocia «on behalf of all the territories for whose international relations the UK is responsible». Esta directriz negociadora del RU no se opone a la de la Comisión, que no exige negociaciones separadas sino a un acuerdo separado en relación con Gibraltar con el acuerdo previo de España.
} 
Otra propuesta que puede tener eficacia inmediata ha sido la de ratificación independiente por el RU de aquellos Convenios de la Conferencia de La Haya que vinculan al RU actualmente por su condición de EM de la UE. Se trata del Convenio de La Haya de 2005 sobre acuerdos de elección de foro, cuya ratificación llegó a realizarse por el RU el 28 de diciembre de 2018, pero de forma condicionada al resultado de las negociaciones del Brexit, para luego ser retirada el 31 de enero de 2020, y el Convenio de La Haya 2007 sobre Cobro internacional de obligaciones alimenticias, ratificado el 31 de diciembre de 2019, pero cuyo instrumento de adhesión ha sido también retirado el 31 de enero de 2020. La retirada de ambos instrumentos de adhesión, tras la firma del Withdrawal Agreement y la apertura de un nuevo período transitorio hasta 31 diciembre de 2020. ha sido realizada sin perjuicio de volver a depositarlos en función de la evolución de las negociaciones y antes de la finalización del período transitorio.

La ratificación del Convenio de La Haya de 2005 sobre acuerdos de elección de foro resulta de interés por su futura aplicación en las relaciones entre el RU y los EEMM de la UE, además de México, Singapur y Montenegro, pero cabe también tener en cuenta sus limitaciones en atención al ámbito material más reducido del Convenio y a que sólo resulta temporalmente aplicable respecto de acuerdos de elección de foro formalizados tras la entrada en vigor del propio Convenio para el Estado que deba de aplicarlo, por lo que los acuerdos de elección de foro celebrados con anterioridad al amparo del Reglamento Bruselas I no podrán pasar automáticamente a estar regidos por el Convenio de La Haya de $2005^{18}$.

En el mismo entorno de la Conferencia de La Haya de DIPr otro instrumento que puede resultar de interés para el RU a largo plazo es el Convenio de 2 de julio de 2019 sobre Reconocimiento y ejecución de sentencias extranjeras en materia civil y mercantil (Judgments Convention 2019). Sin embargo, el Convenio no se encuentra en vigor y además sólo cuenta por el momento con dos firmas (Uruguay y Ucrania) y no cuenta con ninguna ratificación o

${ }^{18}$ Vid. Campuzano Díaz, B. Los acuerdos de elección de foro. Un análisis comparado de su regulación en el Convenio de La Haya de 2005 y en el Reglamento 1215/2012, Granada, Comares, 2018, pp. 52-80 y reseña de Checa Martínez M. en REEI, 2019, núm. 37; Ahmed, M., Beaumont, P. «Exclusive choice of court agreements: some issues on The Hague Convention on choice of court agreements and its relationship with the Brussels I recast especially anti-suit injunctions, concurrent proceedings and the implications of Brexit», JPIL, 2017, pp. 386-410. 
adhesión. Si el Convenio fue elaborado a lo largo de un proceso superior a la década (tras la aprobación del Convenio de La Haya sobre Acuerdos de elección de foro de 2005 que vendría a ser su antecedente) pensando en las relaciones de EM de la UE con terceros Estados, y particularmente en relación con EEUU, el Brexit añade una dimensión adicional de futuro a este Convenio, pero precisamente por esta razón la UE se encontrará ante la necesidad de estudiar aún más detenidamente las implicaciones de la ratificación de este Convenio.

\section{Las soluciones unilaterales del RU para el caso de inexistencia de un nuevo Acuerdo}

Las dificultades de aprobación por el Parlamento británico del proyecto de Acuerdo de Retirada pronto motivaron otra estrategia en el negociador británico dirigida a encontrar vías de presión sobre la contraparte europea mediante soluciones alternativas para el escenario de no-deal. En este sentido, el legislador británico dentro de los preparativos para un no-deal ha procedido a la transposición, reforma y, en su caso, derogación, de aquellas disposiciones contenidas en los Reglamentos de la UE de cooperación judicial civil que, de otro modo, seguirían formalmente en vigor de manera inalterada por el efecto inercial o de conservación de vigencia de la legislación europea (retained EU legislation) que produce la European Union (Withdrawal) Act 2018, -conocida también como la Great Repeal Bill por haber sido propuesta inicialmente con este título-.

Así, ha sido prevista la derogación con efectos para Inglaterra y Gales e Irlanda del Norte en la fecha de finalización del período transitorio (exit day) del Reglamento 1215/2012 (Bruselas I bis) en The Civil Jurisdiction and Judgments (Amendment) (EU Exit) Regulations 2019 ${ }^{19}$, aunque se mantienen las reglas jurisdiccionales relativas a la protección del consumidor y del trabajador, así como la definición del domicilio de personas jurídicas a los efectos de la determinación de la competencia judicial internacional, en forma de nuevas disposiciones en la Civil Jurisdiction and Judgments Act $1982^{20}$, modificaciones que serán aplicables también a las situaciones que afecten a partes domiciliadas en otra parte el Reino Unido -intra UK cases-. Es mucho lo que se perderá en

\footnotetext{
${ }^{19}$ Statutory Instruments 2019 No 479 y No 1338.

${ }^{20}$ Vigente en el RU desde 1 de enero de 1987, como primer instrumento de DIPr de la UE con eficacia en el Reino Unido.
} 
materia de cooperación judicial civil si finalmente el RU, como todo parece indicar, queda desligado del Reglamento Bruselas I bis ${ }^{21}$. Es difícil imaginar las razones por las que el negociador británico está dispuesto a sacrificar en la negociación una nueva vigencia bilateral del Reglamento Bruselas I bis. La existencia del Reglamento Bruselas I bis ha servido en el pasado para consolidar la primacía de Londres como capital judicial de Europa (Commercial Court como sub-división de la Queen's Bench de la High Court) garantizando la eficacia exclusiva de los acuerdos de sumisión en favor de los tribunales ingleses y el reconocimiento en el resto de la UE de las sentencias que en consecuencia pudieran adoptar los tribunales ingleses. Una eficacia no exclusiva de los acuerdos de jurisdicción a los tribunales de Londres, el riesgo consiguiente de procesos paralelos y un mayor grado de incertidumbre sobre el régimen de reconocimiento y ejecución eventualmente aplicable en cada uno de los EEMM podrían tener un efecto potenciador de otras capitales judiciales europeas -París, Amsterdam, Brussels, Frankfurt y otras capitales europeas ha creado o están en proceso de crear tribunales comerciales internacionales que puedan asumir parte de la litigación que hasta ahora asumía Londres ${ }^{22}-$. No sucede lo mismo en el ámbito del arbitraje comercial internacional por ser materia para la que no existe en realidad legislación de la UE. Si la aplicación bilateral del Reglamento Bruselas I bis quedara finalmente descartada cabe pensar que la vuelta al excesivo particularismo de las reglas sobre service of process como criterios de competencia judicial internacional en el Derecho

\footnotetext{
${ }^{21}$ Sobre el retroceso en el ámbito procesal civil internacional que significa la inaplicabilidad futura del Reglamento Bruselas I bis vid. Dickinson, A. «Back to the Future: The UK's EU Exit and the Conflict of Laws», JPIL, 2016, pp. 195-210; ID. «Close the Door on Your Way Out. Free Movement of Judgements in Civil Matters. A "Brexit" Case Study", ZEuP, 2017, pp. 539-568; LeIN, E. «Unchartered Territory? A Few Thoughts on Private International Law post Brexit», Yearbook PIL, 2015/2016, pp. 33-48; Hess, B. «Back to the Past: Brexit und das europäische internationale Privat- und Verfahrensrecht», IPRax, 2016, pp. 409-418; Sonnentag, M.Die Konsequenzen des Brexits für das Internationale Privat- und Zivilverfahrensrecht, Tübingen, Mohr Siebeck, 2017, pp. 80-84. RüHL, G. «Judicial Cooperation in Civil and Commercial matters after Brexit: Which way forward», ICLQ, 2018, 99-128.

22 Así, la Chambre international del Tribunal de commerce de París como primera instancia y la Chambre international de la Cour d'appel de París como segunda instancia (vid. Kramer, X. «A Common Discourse in European Private International Law. A view from the Court System», en Von Hein, J. Kieninger,E.-M., Rühl, G. How European is European Private International Law, Cambridge, Intersentia, 2019, pp. 230-233).
} 
inglés (statutory rules) y a las soluciones algo anticuadas de la jurisprudencia del Common Law en materia de reconocimiento y ejecución respecto de sentencias dictadas en terceros países, motivarán la aparición en el RU de nuevas regulaciones de DIPR, sobre todo, en materia de reconocimiento y ejecución de sentencias extranjeras que mejoren la existentes, aplicables ahora sólo en defecto de instrumentos europeos ${ }^{23}$.

Los Reglamentos Bruselas II bis en materia matrimonial y de responsabilidad parental y Bruselas III en materia de obligaciones alimenticias quedan derogados también para Inglaterra y Gales e Irlanda del Norte en lo relativo al reconocimiento de decisiones y cooperación de autoridades, pero los criterios de competencia judicial internacional resultan modificados en la Jurisdiction and Judgments (Family) (Amendment etc.) (EU Exit) Regulations $2019^{24}$. En lo relativo al divorcio se ha previsto, para el caso en que no se produzcan nuevos acuerdos, la determinación de la jurisdicción internacional de manera paralela a lo previsto por el Art. 3 del Reglamento Bruselas II bis, pero añadiendo expresamente el foro del domicilio de cualquiera de las partes («either to the parties of the marriage is domiciled in England and Wales»), que ahora para los tribunales ingleses resultaba adicional sólo en casos de competencia residual (Art. 7); es decir, el criterio del sole domicile of eitherparty sólo ha venido siendo aplicable cuando ningún otro EM de la UE tiene jurisdicción de conformidad con lo previsto en el Art. 3 del Reglamento Bruselas II bis. La propuesta no se acompaña de normas sobre litispendencia, quedando derogadas las contenidas en el Reglamento Bruselas II bis, de manera que las situaciones de procesos paralelos de divorcio podrán producirse con más facilidad en el futuro, decidiendo los tribunales ingleses acerca de la cuestión conforme a sus reglas tradicionales sobre el foro de la conexión más estrecha y forum non conveniens. El reconocimiento de los divorcios obtenidos en el extranjero pasaría a estar regulado, cuando así sea posible, por el Convenio de La Haya de 1970 sobre el reconocimiento de divorcios y de separaciones legales, incorporado al ordenamiento del RU por la Family Law Act 1986 y que se

\footnotetext{
${ }^{23}$ Un retorno a las reglas del Common Law que no son siempre bien conocidas y que pueden presentar ventajas por su flexibilidad, pero también desventajas, BRIGGS, A. «Brexit and Private International Law: An English Perspective», RDIPP, 2019, pp. 261-283.

${ }^{24} \mathrm{La}$ Civil Partnership and Marriage (Same Sex Couples) (Jurisdiction and Judgments) (Amendment etc.) (EU Exit) Regulations 2019 establece las mismas reglas en relación con el divorcio de matrimonios del mismo sexo y la disolución de uniones civiles.
} 
encuentra en vigor en otros doce Estados miembros de la UE (Chipre, República Checa, Dinamarca, Estonia, Finlandia, Italia, Luxemburgo, Países Bajos, Polonia, Portugal, Eslovaquia y Suecia); en el resto de Estados miembros el reconocimiento de las decisiones judiciales inglesas de divorcio deberá realizarse según las normas nacionales de DIPR ${ }^{25}$.

En materia de responsabilidad parental sería aplicable el Convenio de La Haya de 1996 relativo a la competencia, la ley aplicable, el reconocimiento, la ejecución y la cooperación en materia de responsabilidad parental y de medidas de protección de los niños, así como el Convenio de 1980 sobre los aspectos civiles de la sustracción internacional de menores, desde luego sin las normas complementarias que incorpora sobre el particular el Reglamento Bruselas II bis. En cuanto a la materia de obligaciones alimenticias la derogación del Reglamento Bruselas III podría quedar paliada al menos parcialmente por la ratificación por el Reino Unido del Convenio de La Haya de 2007 sobre Cobro internacional de alimentos, no desde luego en lo relativo a la futura eficacia de acuerdos de jurisdicción ya pactados al amparo de lo previsto en el Reglamento Bruselas III.

El Reglamento europeo de insolvencia ha sido parcialmente derogado y también parcialmente modificado para Inglaterra y Gales e Irlanda del Norte en la Insolvency (Amendment) (EU Exit) Regulations 2019 y la Insolvency (Amendment) (EU Exit) (No 2) Regulations 201926; en particular, se derogan las disposiciones relativas al reconocimiento de la apertura de procedimientos de insolvencia en los EEMM de la UE, pero en materia de competencia judicial internacional se modifican o adaptan los criterios jurisdiccionales para la apertura de procedimientos de insolvencia previstos en el Art. 1 del Reglamento insolvencia, que se añadirán a los previstos en el DIPR del RU. Así, los tribunales del RU tendrán competencia judicial internacional si el COMI (centro de intereses principales) del deudor se encuentra en el RU, si el deudor tiene un establecimiento en el RU, o si se cumplen las condiciones previstas por el DIPR de fuente propia en el RU. La situación futura puede ser en efecto de excesiva incertidumbre. Entre los actuales EEMM de la UE, sólo RU (Cross-Border Insolvency Regulations 2006), -y también Gibraltar (Cross Border

\footnotetext{
${ }^{25}$ En el caso español las previstas en los Arts. 41-61 de la Ley 29/2015, de 30 de julio, de cooperación jurídica internacional en materia civil.

26 Statutory Instruments 2019, No 146 y No 1459.
} 
Insolvencies Regulations 2014)-, Grecia (2010), Polonia (2003), Rumanía (2002) y Eslovenia (2007) tienen regulaciones nacionales de DIPR similares inspiradas en la Ley modelo de UNCITRAL sobre Insolvencia transfronteriza, pero la Ley modelo no regula la competencia judicial internacional ni las cuestiones de ley aplicable ${ }^{27}$. En cuanto al reconocimiento de las decisiones extranjeras de apertura de procedimiento concursal, de la condición y poderes del administrador concursal y otras resoluciones extranjeras en materia concursal, los EEMM de la UE tendrán que aplicar en relación con el RU las soluciones previstas en su DIPR nacional ${ }^{28}$.

Quedarán también sin aplicación los Reglamentos europeos sobre procedimientos especiales (Reglamento 805/2004 sobre título ejecutivo europeo, Reglamento 1896/2006 sobre procedimiento monitorio europeo y Reglamento 861/2007 sobre reclamaciones de menor cuantía) ${ }^{29}$; así como los Reglamentos europeos 1393/2007 sobre notificaciones judiciales y extrajudiciales y 1206/2001 sobre obtención de pruebas en el extranjero ${ }^{30}$. La sustitución del Reglamento 1393/2007 de 13 de noviembre de 2007 sobre notificaciones judiciales por el Convenio de La Haya de 1965 y la sustitución del Reglamento 1206/2001 de 28 de mayo de 2001 por el Convenio de La Haya de 1970 sobre obtención de pruebas en el extranjero es otro retroceso técnico que tampoco parece en consonancia con la posición de Londres como capital judicial europea.

Una vez que el RU deje de ser miembro de la UE tampoco serían aplicables al mismo los Convenios que le obligan como consecuencia de la ratificación

\footnotetext{
${ }^{27}$ Adelus, E. «Global law-making in insolvency law: the role for the United Nations Commission for International Trade Law», Uniform L. R., 2019, pp. 175-213; R. BoRK, «The European Insolvency Regulation and the Uncitral Model Law on Cross-Border Insolvency», Int. Insolv. Rev., 2017, pp. 246-269; McCormack, G. Anderson, H. «Brexit and its implication for restructuring and corporate insolvency in the UK», Journal of Business Law, 2017, pp. 533-556. ${ }^{28}$ En el caso de España las previstas en los Arts. 220-226 de la Ley 22/2003, de 9 de julio, Concursal (vid. Umfreville Ch.y otros, «Recognition of UK Insolvency proceedings post-brexit: the impact of a no-deal scenario», Int. Insolv. Rev., 2018, pp. 422-444).

${ }^{29}$ Derogados a partir del Brexit day para todo el Reino Unido en The European Enforcement Order, European Order for Payment and European Small Claims Procedure (Amendment Etc.) (EU Exit) Regulations 2018, S.I. No 1311.

${ }^{30}$ Se encuentran derogados a partir del Brexit day con eficacia territorial para todo el Reino Unido por la Service of Documents and Taking of Evidence in Civil and Commercial Matters Revocation and saving provision) (EU Exit) Regulations 2018, S.I. No 1257.
} 
o adhesión por la UE: a) Acuerdos entre EU y Dinamarca para la aplicación de: Reglamento Bruselas I bis, Reglamento Bruselas III y Reglamento de notificaciones judiciales y extrajudiciales; b) Convenio de Lugano 2007 aplicable en relación con Suiza, Noruega e Islandia; c) Convenio de La Haya de 2005 sobre acuerdos de elección de foro; sin embargo, ese resultado se intentará evitar con la ratificación independiente del Reino Unido y las disposiciones ya adoptadas en la Civil Jurisdiction and Judgments (Hague Convention on Choice of Court Agreements 2005) (EU Exit) Regulations 2018; d) Convenio de La Haya de 23 de noviembre de 2007 sobre Cobro Internacional de Alimentos.

Por el contrario, en el ámbito de la ley aplicable no siendo necesaria la reciprocidad, ha sido prevista la transposición y, en consecuencia, la continuidad en todo el Reino Unido de las reglas existentes hasta el momento en los Reglamentos 593/2008 (Roma I) y 864/2007 (Roma II), en The Law Applicable to Contractual Obligations and Non-Contractual Obligations (Amendment etc.) (EU Exit) Regulations 2019 ${ }^{31}$. Este es uno de los pocos ámbitos donde la continuidad parecía la solución más natural -prescindir de estas regulaciones sobre conflicto de leyes sería un retroceso difícilmente justificable- y además queda asegurada de la manera más sencilla por el cauce unilateral sin necesidad de ulteriores acuerdos. El abandono de estas regulaciones sobre conflicto de leyes sería aún más inexplicable si se tiene en cuenta la impronta que el Common Law ha tenido en su elaboración y desarrollo, aunque cabría sostener que la influencia no ha sido siempre precisamente la inglesa (proper law of the contract) sino la norteamericana tanto en el ámbito contractual (most significant relationship) como en el ámbito extracontractual (proper law of the tort). La continuidad en todo caso sólo será aparente porque la interpretación podrá comenzar a divergir a uno y otro lado del Canal al asumir el Tribunal Supremo del Reino Unido, a partir del Brexit day, la posición de última instancia interpretadora de los instrumentos europeos retenidos en la legislación del Reino Unido (la jurisprudencia del TJUE tendrá en el futuro una sombra alargada en el RU, pero los presupuestos para el inicio de la divergencia interpretativa ya están establecidos).

La aprobación final del Acuerdo de Retirada -European Union (Withdrawal Agreement) Act 2020 - ha tenido el efecto de modificar el día de eficacia de toda esta legislación secundaria británica que responde a la denominación de

${ }^{31}$ S. I. $2019 \mathrm{~N}^{\circ} 834$. 
EU Exit Regulations (se trata de statutory instruments, es decir, subsidiary legislation en la terminología inglesa) a la finalización del período transitorio el 31 de diciembre de 2020, siempre que el nuevo modelo de relaciones entre el RU y la UE no prevea otra consecuencia. No parece que esto último vaya a ocurrir, ya que de producirse algún avance parece que será en contextos multilaterales como la Conferencia de La Haya de DIPR o en relación con el Convenio de Lugano de 2007, de modo que las EU Exit Regulations inicialmente pensadas para un escenario de no-deal (es decir, sin Withdrawal Agreement) servirán igualmente en el entorno de hard brexit que surgirá del fracaso en conseguir un nuevo modelo de relaciones entre el RU y la UE.

\section{LA CONVENIENCIA DE UN ACUERDO SEPARADO ENTRE EL RU Y LA UE PARA GIBRALTAR}

La existencia de un nuevo modelo de relaciones futuras entre el RU y la UE en relación con Gibraltar quedará condicionada al mal llamado "derecho de "veto" que el Estado español tiene reconocida por la UE en lo relativo a este territorio y que, en realidad, se concreta en que un Acuerdo con relación a Gibraltar sólo será posible si existe un acuerdo separado y de la previa aceptación del Estado español ${ }^{32}$. Las Directrices de negociación publicadas por la Comisión el 3.02.2020 («authorising the opening of negotiations for a new partnership with the United Kingdom») resultan especialmente claras en relación a Gibraltar. Recordando la Declaración del Consejo y la Comisión de 25 de noviembre de 2018, las directrices expresan que Gibraltar no será incluido en el ámbito de aplicación territorial de los acuerdos a los que pueda llegar la Unión con el Reino Unido, aunque esto no impedirá que puedan existir acuerdos separados entre el Reino Unido y la UE con relación a Gibraltar, acuerdos que requerirán el consentimiento previo («prior agreement») de España. En realidad, esto quiere decir que el Acuerdo en relación con Gibraltar puede ser muy diferente al que hipotéticamente pueda ser alcanzado en relación con el RU, lo cual ofrece muchas oportunidades pero que tendrán que ser resultado de un proceso negociador particular entre RU representando a Gibraltar por un lado y la UE y

\footnotetext{
${ }^{32}$ La necesidad de previo acuerdo de España en relación a Gibraltar dentro del proceso de negociación de la salida del Reino Unido se remonta a las Directrices de la Comisión de 29 de abril de 2017 (vid. Del Valle GÁlvez, A. «Brexit negotiations and Gibraltar: Time for a Modus Vivendi», Cuadernos de Gibraltar / Gibraltar Reports, no 3, 2017, pp. 19-26.
} 
España de otro lado. Las autoridades Gibraltareñas siempre han expresado su oposición a esta negociación separada de la situación post-Brexit de Gibraltar respecto a la del propio RU, quizás por el peligro inherente a que avances del RU en la negociación sean logrados gracias a retrocesos en relación a Gibraltar, pero al mismo tiempo han expresado que un Acuerdo de libre comercio como el perseguido por el RU no es interesante para Gibraltar (que no tiene actividad exportadora y nunca ha participado de la Unión Aduanera) y que, por el contrario, sus objetivos principales serían, en primer lugar, mantener la fluidez de paso en la frontera con España por la que atraviesa diariamente el $40 \%$ de su fuerza laboral (un resultado que podría quedar garantizado, entre otros mecanismos, por su participación en el espacio Schengen, aunque el RU no participe del mismo; recuérdese que microestados que no son parte de la UE como Mónaco o Liechtenstein participan del espacio Schengen) y, en segundo lugar, conservar el acceso al mercado único de servicios en la UE (aunque esto sólo represente menos del 10\% de su mercado de prestación de servicios puesto que su principal mercado es el propio RU respecto del cual ya se ha asegurado acceso directo) $)^{33}$.

Si bien la Declaración política en ningún momento menciona a Gibraltar, el Protocolo sobre Gibraltar del Acuerdo de Retirada establece que su Art. $1^{\circ}$ sobre derechos de los ciudadanos (segunda parte del Acuerdo de Retirada) es el único que tendrá vigencia más allá del período transitorio y es precisamente en relación con los futuros derechos de movilidad de los ciudadanos con los que se vincula la futura negociación de la pervivencia de los instrumentos de cooperación judicial en materia de familia. En este sentido, la continuidad de la aplicación de los instrumentos conocidos como Bruselas II bis y Bruselas III (incluida la ratificación por el RU del Convenio de La Haya de 2007 sobre alimentos y su lógica extensión al territorio de Gibraltar) permitirá la cooperación judicial entre autoridades españolas y gibraltareñas de modo similar a como ha venido desarrollándose hasta la fecha ${ }^{34}$. Es más, nada impediría que el modelo de cooperación judicial civil internacional finalmente aplicable en relación con Gibraltar fuese más amplio que el aplicable en relación al propio

${ }^{33}$ House of Lords, European Union Committee, Brexit: Gibraltar, 13th Report of Session 2016-17, 1 Marzo 2017.

34 A. Borras Rodríguez, «El Brexit y Gibraltar: la perspectiva de las personas físicas y jurídicas», Martín, M. y Martin, J. (Coords) El Brexity Gibraltar: un reto con oportunidades conjuntas, Madrid, Ministerio de Asuntos Exteriores y de Cooperación de España, 2017, pp. 201-218. 
Reino Unido, en la medida en que los acuerdos respecto de Gibraltar deben ser separados de los alcanzados respecto a Reino Unido, aunque siempre con la aceptación previa de España.

En defecto de nuevos acuerdos en materia de cooperación judicial civil en relación con Gibraltar se impone la necesidad de una definitiva ratificación por el Reino Unido del Convenio de La Haya sobre acuerdos de elección de foro de 2005 y del Convenio de La Haya sobre Cobro internacional de alimentos de 2007 con efectos desde la finalización del período transitorio, así como la extensión de ambos respecto a Gibraltar (y alguna extensión más como la relativa al Convenio de La Haya de 1980 sobre sustracción internacional de menores o al Convenio de La Haya de 1993 relativo a la protección del niño y a la cooperación en materia de adopción internacional). El 31 de julio de 2019 el Reino Unido ya extendió el ámbito de aplicación de ambos convenios (Convenio de La Haya de Acuerdos de elección de foro de 2005 y Convenio de La Haya sobre Cobro internacional de alimentos de 2007) al territorio de Gibraltar, de forma condicionada a que el Acuerdo de Retirada no fuese aprobado, motivo por el que la ratificación fue retirada el 31.01.2020, sin perjuicio de poder volver a formalizarla antes de la finalización del período transitorio.

Desde luego, si finalmente la adhesión del RU al Convenio de Lugano de 2007 fuese posible, aunque ya se ha señalado que la entrada en vigor podría demorarse por la cadena de ratificaciones necesarias posteriores a la adhesión del RU como parte contratante independiente, la extensión a Gibraltar resulta esencial porque es el único modo de salvar el contenido fundamental del régimen actualmente aplicable bajo el Reglamento 1215/2012 (Bruselas I bis) en materia civil y mercantil (en realidad la versión anterior del mismo conforme al Reglamento 44/2001).

En ausencia de los acuerdos o nuevos instrumentos antes mencionados, la aplicación del DIPR gibraltareño será fuerte de incertidumbre por la mayor indeterminación de las reglas existentes, consistentes en la aplicación de la propia legislación gibraltareña cuando exista, la legislación inglesa que pueda tener eficacia supletoria (por ejemplo, las reglas jurisdiccionales contenidas en la Civil Procedure Rules de 1998) o la jurisprudencia del Common Law (por ejemplo, el criterio jurisdiccional de la notificación de la demanda al demando presente en la jurisdicción -transient jurisdiction-, la excepción del forum non con- 
veniens o la vuelta a la disponibilidad de anti-suit injunctions frente a la jurisdicción de EEMM de la UE), teniendo en cuenta la jurisdicción del Privy Council en Londres como última instancia en relación con las decisiones judiciales de los overseas territories (es decir, conoce de los recursos frente a las decisiones de la Court of Appeal de Gibraltar) ${ }^{35}$.

La European Union (Withdrawal Agreement) Act 2020 de Gibraltar no prevé disposiciones específicas en materia de cooperación judicial internacional y los Reglamentos de la UE en consecuencia son retained legislation hasta que sean modificados o derogados por legislación secundaria con efectos a partir del final del período transitorio ${ }^{36}$. Como ya se ha mencionado, no será posible la pervivencia de los instrumentos procesales de DIPR de la UE (implementados en Gibraltar fundamentalmente por la Civil Jurisdiction and Judgments Act 1993, -modificada por última vez en 2018 a los efectos de dar aplicación a la ratificación europea del Convenio de La Haya de 2007 sobre Cobro internacional de alimentos-) si necesitan de la reciprocidad para su funcionamiento y, por el contrario, sí podrán hacerlo los Reglamentos sobre ley aplicable (Roma I sobre ley aplicable a las obligaciones contractuales y Roma II sobre ley aplicable a las obligaciones extracontractuales).

El próximo año se convierte por tanto en esencial para la configuración del nuevo modelo de cooperación judicial civil internacional en Gibraltar. La existencia de un nuevo Acuerdo entre el RU y la UE en relación a Gibraltar puede albergar un régimen de cooperación judicial civil incluso más amplio que el que pueda ser diseñado para el propio RU, por ejemplo, y dicho sea sólo como objetivo mínimo, prolongando la aplicación bilateral de los Reglamentos Bruselas II bis en materia matrimonial y de responsabilidad parental, así como el Reglamento Bruselas III en materia de alimentos.

\footnotetext{
${ }^{35}$ La Sentencia del Privy Council en el asunto Vizcaya Partners Ltd, v. Picard (2016) sobre el reconocimiento en Gibraltar de una sentencia dictada en Nueva York en relación con el caso Madoff muestra claramente las diferencias entre la complejidad de las reglas del Common Law y la seguridad jurídica que aporta el Reglamento Bruselas I bis (vid. KupELYANTs, H. «Implication of Jurisdiction Agreements», Cambridge L. J., 2016, pp. 216-219).

${ }^{36}$ Además, deberán tenerse en cuenta las siguientes disposiciones legislativas (Acts and Regulations) previamente aprobadas en Gibraltar, mencionadas aquí en orden temporal descendente: European Union Withdrawal (Application of International Agreements) Act 2019, Challenges to Validity of EU Instruments (EU Exit) Regulations 2019, European Union Laws (Voluntary Implementation) Act 2019, European Union (Withdrawal Agreement) Act 2019.
} 
En defecto de nuevo Acuerdo aplicable a Gibraltar, las opciones pasan fundamentalmente por: a) la adhesión propia del RU y extensión a Gibraltar del Convenio de La Haya de 2005 sobre acuerdos de elección de foro y el Convenio de La Haya de 2007 sobre Cobro internacional de alimentos; b) la adhesión por el RU y extensión a Gibraltar del Convenio de Lugano 2007, pudiendo a medio plazo ser una alternativa razonable a la actual aplicación del Reglamento Bruselas I bis.

Finalmente, será también la oportunidad para la regulación por Gibraltar de fuentes propias en materia de DIPR ${ }^{37}$. En relación con esta posibilidad cabe pensar en primer lugar en un alineamiento regulatorio de Gibraltar con el DIPR existente en RU y su futura evolución (no cabe olvidar que el RU es el principal mercado de Gibraltar -hasta un $90 \%$ - a través de la prestación directa de servicios financieros, aseguradores, de juego en línea, etc.) ${ }^{38}$. Por otra parte, cabe también pensar que en, algunas materias, la existencia de distintas necesidades de regulación pueda llevar a Gibraltar a una regulación más cercana a lo previsto en otras jurisdicciones offshore como Jersey o Guernsey que, al no pertenecer a la UE, nunca han participado de la aplicación de los instrumentos de DIPr de la UE. Una orientación hacia este último tipo de necesidades ya la podemos encontrar en la Gibraltar Trusts -Private International Law-Act de 2015 o en las normas de DIPR incluidas en la Gibraltar Private Foundations Act $2017^{39}$.

\footnotetext{
${ }^{37}$ Las existentes son en su inmensa mayoría anteriores a la entrada de Gibraltar en la UE: Judgments (Reciprocal Enforcement) Act 1935, Maintenance Orders (Reciprocal Enforcement) Act 1973.

${ }^{38}$ Un ejemplo de ese alineamiento ha sido la implementación por Gibraltar de la Ley modelo de Uncitral sobre Insolvencia transfronteriza en la Insolvencies (Cross Border Insolvencies) Regulations 2014, siguiendo aquí al RU que ya legisló en este sentido en 2006 (Cross Border Insolvencies Regulations 2006).

${ }^{39}$ Harris, J., Morrison, M. «Brexit and the offshore world», Trusts and Trustees, 2017, pp. 259-262.
} 


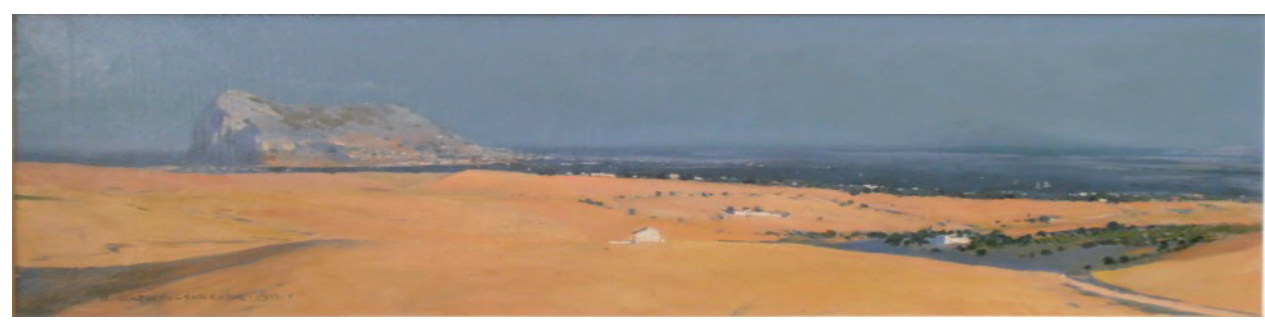

\section{Cuadernos de Gibraltar Gibraltar Reports}

\section{\#03 | 2018-2019}

\section{Sumario}

Table of Contents

\section{CONFERENCIAS DE EXCELENCIA}

Luis Norberto GONZÁLEZ ALONSO, El Brexit y la Unión Europea: panorama de problemáticas, 2016-2019

\section{ESTUDIOS}

Juan Antonio YÁÑEZ-BARNUEVO, Foreign Minister Fernando Morán Addresses the Question of Gibraltar Inmaculada GONZÁLEZ GARCÍA; Miguel ACOSTA SÁNCHEZ, The Consequences of Brexit for Gibraltar, an Overview Polly Ruth POLAK, The Road to Brexit: Ten UK Procedures towards Leaving the EU

Alejandro DEL VALLE GÁLVEZ, Gibraltar, ¿costa española? Por una reformulación de la teoría de la ‘Costa seca' sobre el puerto y las aguas en torno al Peñón

Inmaculada GONZÁLEZ GARCÍA, Gibraltar, Land Reclamation, the Environment and Brexit

Miguel CHECA MARTÍNEZ, Brexit y Cooperación Judicial Civil Internacional: opciones para Gibraltar

Fernando LOZANO CONTRERAS, España, Gibraltar y el Reino Unido en la negociación del Brexit - ¿Viejos problemas, nuevas soluciones? Ángel BALLESTEROS BARROS, El Brexit y la Libertad de Establecimiento de Sociedades en la UE: el caso de Gibraltar

Álvaro CHECA RODRÍGUEZ, The Bilateral Tax Treaty System between the United Kingdom and Spain Regarding Gibraltar: another Step in Gibraltar's Quest for De-Listing as a Tax Haven

\section{ÁGORA}

Antonio GARCÍA FERRER, Las negociaciones sobre el Brexit y Gibraltar. Perspectiva del Ministerio de Asuntos Exteriores, UE y Cooperación de España

Fabian PICARDO, Cómo se ve hoy el Gibraltar de mañana

Luis ROMERO BARTUMEUS, El Consulado de España en Gibraltar. Una historia casi desconocida

Antonio PÉREZ GIRÓN, El exilio interior del pueblo de Gibraltar y el origen de la ciudad de San Roque

Alejandro DEL VALLE GÁLVEZ; Inmaculada GONZÁLEZ GARCÍA; Jesús VERDÚ BAEZA, Claves sobre la singularidad de La Línea de la Concepción a la luz del Derecho Internacional y del Derecho Europeo - Informe previo

Peter MONTEGRIFFO, Perspectivas gibraltareñas sobre el Brexit, su desenlace definitiva y los futuros deseables para Gibraltar y el Campo Joseph GARCÍA, Brexit: Spain and Gibraltar - Welcoming Address

Juan Carlos RUIZ BOIX, El Brexit y Gibraltar, reflexiones desde el Campo de Gibraltar

José Juan FRANCO RODRÍGUEZ; Juan CARMONA DE CÓZAR; Brian REYES, Mesa Redonda - Campo de Gibraltar, cooperación transfronteriza y trabajadores fronterizos tras el Brexit

Juan Antonio YÁÑEZ-BARNUEVO, España, Reino Unido y Gibraltar: las oportunidades del Brexit

\section{RECENSIONES}

José BENEROSO SANTOS, Franco en Gibraltar, marzo de 1935. Antecedentes, desarrollo y consecuencias de una conspiración silenciada, por Luis ROMERO BARTUMEUS

Magdalena M. MARTÍN MARTÍNEZ; J. MARTÍN Y PÉREZ DE NANCLARES (Coordinadores), El Brexit y Gibraltar. Un reto con oportunidades conjuntas, por Carolina JIMÉNEZ SÁNCHEZ

Luis Ernesto OROZCO TORRES y César VILLEGAS DELGADO (Coordinadores Generales), Europa y España frente al Brexit, Retos y Alternativas, por Casilda RUEDA FERNÁNDEZ
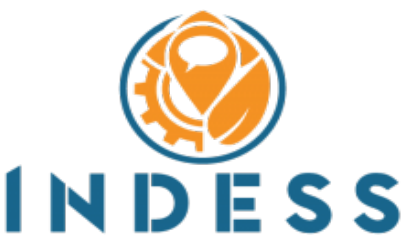

INSTITUTO UNIVERSITARIO DE INVESTIGACIÓN

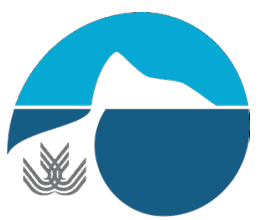

AUGibraltar

Aula Univer Gibraltar - Campo de Gibraltar

CÁTEDRA JEAN MONNET INMIGRACIÓN Y FRONTERAS DERECHO DE LA UNIÓN EUROPEA

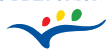

EDUCACIÓN DE LA UNIÓN EUROPEA

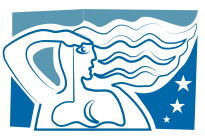

ESTUDIOS

INTERNACIONALES Y EUROPEOS

Centro de Estudios Internacionales y Europeo del Área del Estrecho SEJ-572 